\title{
ESTRESSE OCUPACIONAL EM POLICIAIS MILITARES DA REGIÃO DO VALE DO PARANHANA - RS
}

\author{
Siana Tiara Petry Cantele* \\ Leticia Horn Oliveira*
}

\begin{abstract}
RESUMO: Este estudo pretendeu verificar se os policiais militares de uma cidade da região do vale do Paranhana, inteiror do Rio Grande do Sul, sofrem de estresse ocupacional. Também foi objetivo da pesquisa compreender se 0 trabalho afeta a vida desses profissionais, identificando quais os fatores geradores de estresse, como também conhecer as estratégias utilizadas pelo policial para lidar com essa situação. 0 método utilizado foi um estudo descritivo, de caráter quantitativo e qualitativo. A investigação deu-se em dois momentos: primeiro, foi aplicada à escala EVENT (Escala de Vulnerabilidade ao Estresse no Trabalho) e os dados foram analisados no programa SPSS 20.0 (Statistical Program for Social Sciences). Já no segundo momento, foi realizada uma entrevista semi-estruturada, somente para os profissionais que apresentaram nível de estresse superior. Participaram da pesquisa 40 policiais militares, de ambos os sexos, com idade entre 25 e 49 anos. Os resultados indicaram que os participantes sofrem de estresse, estando mais vulneráveis os policiais que realizam serviço externo. Constatou-se que a causa maior do estresse no trabalho dos policiais são questões relacionadas à infraestrutura e rotina, tais como a falta de equipamentos, materiais precários e mudanças nas escalas de horário de trabalho. Sendo assim, é fundamental que se tenha um olhar cuidadoso para esses profissionais e que sejam desenvolvidas estratégias para o suporte emocional e social dos trabalhadores dessa categoria, bem como mudanças na infraestrutura de trabalho.
\end{abstract}

PALAVRAS-CHAVE: Psicologia; Estresse ocupacional; Policial militar.

\section{OCCUPATIONAL STRESS OF MILITARY POLICE IN THE VALE DO PARANHANA REGION, BRAZIL}

\begin{abstract}
Current analysis discusses whether military police of a town in the Vale do Paranhana, interior of the state of Rio Grande do Sul, Brazil, are under occupational stress. Research also debates whether their professional work affects their lives by identifying the stress-generation factors and detecting strategies to cope with them. The descriptive, quantitative and qualitative method was employed with EVENT (Work Stress Vulnerability Scale) and data were analyzed by Statistical Program for Social Sciences (SPSS) 20.0. A semi-structured interview was then undertaken with professionals with high stress rates. Forty military police, males and females, aged between 25 and 49 years, participated in current research. Results showed that participants were stressed, especially those allotted to external work. Main causes for stress were issues related to infrastructure and work routine, such as lack of equipments, precarious material and changes in work shifts. More care should be devoted to the professionals, while strategies should be adopted for emotional and social props, coupled to changes in the infrastructure.
\end{abstract}

KEYWORDS: Psychology. Occupational stress. Military police.

\section{INTRODUÇÃO}

0 estresse no trabalho é considerado um fator importante que influencia o ser humano a ter certos tipos de comportamentos, acarretando 0 descontrole de todo o organismo do indivíduo. Desse modo, entende-se que o estresse é causado quando

\footnotetext{
Graduada em Psicologia pela Faccat - Faculdades Integradas de Taquara, Taquara (RS), Brasil.

** Doutoranda em Psicologia pela Pontifícia Universidade Católica (PUCRS); Docente nas Faculdades Integradas de Taquara (FACCAT), na Faculdade São Francisco de Assis (UNIFIN) e nos cursos de Especialização em Psicologia Escolar (CAPE) e Psicologia Organizacional (IDG), Brasil; E-mail: leticiahornoliveira@yahoo.com.br.
} 
doses excessivas e intensas extrapolam a capacidade do corpo. Sabe-se que o estresse no trabalho é um quadro disfuncional, provocando um desgaste extremo ao corpo, por forte tensão crônica, ou tensão aguda que enfrenta diariamente, pela grande intensidade de pressão imposta pelas situações laborais. (CAMELO; ANGERAMI, 2007; FERREIRA; OLIVEIRA, 2013; MARRAS; VELOSO, 2012).

Hans Selye, estudante de medicina na Universidade de Praga, foi quem utilizou o termo na área da saúde pela primeira vez em 1926 (SELYE, 1984 apud GOMES; AZAMBUJA, 2009; GOMES et al., 2013). 0 pesquisador denominou 0 estresse de Síndrome de se sentir doente, uma vez que, para ele, era mais importante tentar entender 0 verdadeiro mecanismo do adoecer, ou seja, aquilo que não estava específico na doença e que ficava de lado. Para 0 estudioso, 0 estresse era um estado manifestado, constituído por alterações específicas produzidas pelo sistema biológico (SELYE, 1965 apud MARRAS; VELOSO, 2012). Ele percebeu que muitas pessoas sofriam de doenças físicas, e todos demonstravam algum sintoma em comum, porque se queixavam de sintomas fisiológicos como: falta de apetite, desânimo e fadiga, entre outros sintomas que acompanhavam a vida do indivíduo. As pesquisas de Selye impulsionaram diversos estudos sobre 0 tema tornando-se um campo distinto e com suas próprias características (LIPP, 2003; PAIVA; GOMES; HELAL, 2015).

0 estresse é definido como um estado de tensão que causa ruptura no equilíbrio interno do organismo. Quando o estresse acontece, a homeostase é quebrada e passa a não existir entrosamento entre vários órgãos do corpo. 0corre um desgaste anormal na máquina humana, provocando uma incapacidade prolongada de a pessoa tolerar, superar ou adaptar as exigências do ambiente de vida. Para o corpo lidar com o problema, acontece um desequilíbrio, e, assim, alguns órgãos trabalham mais e outros menos. 0 organismo de forma natural tenta alcançar novamente 0 equilíbrio perdido, buscando, então, automaticamente, restabelecer aquilo que está desajustado no interior do corpo. 0 equilíbrio dos órgãos do corpo pode retornar quando houver o término da fonte de estresse ou quando 0 indivíduo encontra estratégias, enfrenta e aprende a lidar com 0 evento estressor. Em alguns casos, nem sempre o equilíbrio retorna a ser o que era anteriormente (LIPP, 2000; MAFFIA; ZILLE, 2013).

Énecessário compreender as fases do estresse, por isso é importante distinguir o bom estresse do estresse ruim, pois 0 estresse é reação comum do próprio corpo, pelo estímulos seguidos do ambiente. 0 estresse então não pode ser considerado totalmente ruim, ele é importante para o funcionamento humano, mas precisa ser adaptado ao organismo. Para isso, é necessário verificar se a pessoa sente-se satisfeita $\mathrm{e}$ excitada durante as tarefas estressantes que enfrenta e perceber como reage depois de passar por elas. 0 processo de estresse foi analisado por Selye em três fases: alerta, resistência e exaustão. A fase de alerta é considerada como positiva, pois os seres humanos entram e saem dessa fase com facilidade. A ansiedade que aparece nesse estágio é necessária para manter 0 indivíduo preparado para agir diante do perigo. 0 ser humano se energiza com a produção da adrenalina. Aqui se iniciam os estímulos estressores, mas 0 organismo busca restaurar o equilíbrio (SELYE, 1965; LIPP, 2000; MARQUES; GASPAROTTO; COELHO, 2015).

Posteriormente, ocorre a fase da resistência que está vinculada a um acúmulo da tensão provocado pela fase anterior, quando a situação não foi plenamente solucionada, o organismo mantém um sinal de alerta pelo desgaste já sofrido e continua predisposto a enfrentar a situação ocorrida. 0 esforço do corpo é para manter uma harmonia interna, resistindo ao evento estressor. Se a energia da pessoa for suficiente, o organismo se recupera. Caso contrário, o processo pode avançar para a terceira fase, a da exaustão, uma fase mais complicada, pois é quando ocorre uma série de sintomas prejudiciais, colocando a pessoa em uma situação de vulnerabilidade, esgotamento, com riscos de adquirir vírus, bactérias e doenças relacionadas ao estresse, ficando o indivíduo incapaz de levar uma rotina normal (LIPP, 2000; MAFFIA; ZILLE, 2013).

Quando 0 indivíduo está na fase da exaustão, é provável que surja a patologia, pois o estresse já 
está agindo sobre 0 organismo há mais tempo, não se conseguindo encerrar o ciclo. 0 nível de resistência vai enfraquecendo, 0 desperdício de energia é muito alto e 0 corpo não consegue manter os níveis saudáveis de adaptação. Nessa condição, mostra-se 0 efeito que 0 estresse tem sobre a saúde do indivíduo, ocorrendo um desgaste e um desequilíbrio interior de forma drástica. A pessoa, neste momento, além de depressão, pode desenvolver doenças graves, como úlceras, pressão alta, insônia, vitiligo, infarto, falta de concentração, falhas de memória, impossibilidade de trabalhar, entre outras. As enfermidades que aparecem na pessoa não estão apenas ligadas ao estresse, mas também à sensibilidade de cada órgão do corpo, desencadeando doenças que antes estavam latentes (MALAGRIS; FIORITO, 2006; RAMIRO et al., 2014).

Até pouco tempo, entendia-se que 0 estresse era formado por essas três fases citadas anteriormente: a fase de alerta, a fase de resistência e a fase da exaustão. Passando praticamente por 15 anos de estudos, no laboratório de stress da PUC em Campinas, a pesquisadora Lipp (2014) identificou outra fase denominada com 0 nome de quaseexaustão. Essa nova nomenclatura está inserida entre a resistência e a exaustão. Assim, desenvolveu-se um modelo quadrifásico para 0 estresse, ampliando 0 antigo modelo elaborado por Selye no ano de 1936 (LIPP, 2014).

Para compreender esta nova fase, de quaseexaustão, pontua-se como um período no qual 0 organismo começa a ceder e não resiste às tensões. Esta fase está caracterizada pelo enfraquecimento do indivíduo que não consegue adaptar ou resistir ao estressor. Nessa fase, momentos de bem-estar, tranquilidade, ansiedade, desconforto e cansaço oscilam. Porém, algumas doenças podem aparecer não de forma tão grave, mas isso significa que a eficácia da resistência já não está adequada. Ao persistirem os estímulos estressores na mesma frequência e intensidade, haverá uma quebra da resistência, e a pessoa entrará na fase de quaseexaustão. Se os estressores não forem retirados ou 0 indivíduo não utilizar estratégias de enfrentamento, 0 estresse passará ao seu último estágio, ou seja, à fase de exaustão, podendo aqui surgir doenças graves que atingirão os órgãos mais vulneráveis do corpo (LIPP, 2010, 2014).

Entende-se que estímulos estressantes são respostas ameaçadoras, que estão relacionadas diretamente com o estresse no ambiente de trabalho. É quando a função ou cargo excedem a capacidade e 0 recurso que 0 profissional adquire para enfrentar tais condições, as demandas de trabalho intensas passam a ser prejudiciais à saúde. Percebe-se que alguns ambientes organizacionais estão propícios para causar estresse ao trabalhador, pela exposição aos eventos estressores, desencadeando reações orgânicas, emocionais na saúde da pessoa. Sabe-se que os trabalhadores que têm tendência à depressão reagem mais vezes ou mais intensamente aos estressores organizacionais, acarretando problemas de baixo desempenho no local de trabalho e disfunções emocionais graves (SAMPAIO; GALASSO, 2002; SISTO et al., 2012).

Qualquer situação que cause um estado emocional forte, uma quebra de equilíbrio interno e exija alguma adaptação imediata pode ser denominada de um evento estressor. 0 desgaste que 0 indivíduo se submete a enfrentar no ambiente de trabalho pode causar doenças, incluindo 0 sofrimento psíquico. Isso se dá pela pressão que a pessoa sofre diariamente, ou seja, um conjunto de sintomas que estão associados ao estresse ocupacional. Este quadro indica que 0 trabalhador está adoecendo, portanto são necessárias as devidas intervenções terapêuticas para minimizar os sintomas do estresse (RANGÉ, 2001; GOMES et al., 2013).

0 estresse causa na pessoa sintomas crônicos e pode levar à síndrome de burnout, uma patologia, que está relacionado às condições atuais de trabalho, pelo estado de tensão emocional e estresse crônico causado pelas condições desfavoráveis e desgastantes da atividade desenvolvida. A síndrome é caracterizada por um esgotamento emocional e físico agudo. Nesse caso, o profissional não consegue atender à demanda que está sob sua responsabilidade no trabalho, e a 
situação passa a ameaçar o seu bem-estar. Essa condição é causada pela rotina prolongada e pela alta carga de tensão (MALLAR; CAPITÃ0, 2004; PAIVA; GOMES; HELAL, 2015).

De acordo com a Organização Mundial de Saúde (OMS), a maior fonte de estresse em relação aos adultos está relacionada à atividade profissional, uma vez que, em cada profissão, ocorrem situações desgastantes que desencadeiam fatores que causam 0 estresse. A manifestação dá-se conforme a exposição do profissional a fatores de risco em seu local de trabalho. Fala-se muito no estresse, que 0 mesmo é considerado uma doença grave, mas pouco tem se feito pelo trabalhador, diante dos conceitos amparados pela OMS. É necessário existir promoção de saúde, bem-estar físico, mental e social (SADIR et al., 2009; FERREIRA; MENDONÇA, 2012).

A profissão de Policial Militar, por exemplo, é considerada uma das categorias de trabalhadores que apresenta maior nível de estresse e risco de vida se comparado com as demais profissões. 0 profissional sofre ao executar sua atividade, tendo sobrecarga de trabalho, problemas nas relações internas da instituição, conflito dos policiais com o Sistema de Justiça e insatisfação com o plano de carreira. Além disso, as pressões impostas pelos mecanismos disciplinares rígidos são consideradas como fontes de alto sofrimento psíquico (SOUZA et al., 2012). 0 militar sofre a influência de vários fatores negativos que causam um estresse extremo. Isso se dá porque esse profissional está constantemente exposto, em sua rotina de trabalho, ao perigo, tendo que intervir diariamente em situação de conflito e tensão. 0 cansaço físico e a falta de equilíbrio emocional também pode levar o profissional a ter atitudes não desejáveis, durante crises e situações caóticas, gerando falta de eficácia no seu desempenho. Esse trabalhador, quando ingressa na carreira, muitas vezes busca 0 "status" que a profissão oferece, mas, ao passar do tempo, o militar depara-se com a falta de reconhecimento da função e a percepção de uma profissão arriscada, uma vez que exerce a atividade em um ambiente desumano, complexo e hostil (CALANZAS, 2010; SOUZA et al.,
2012).

Em muitos casos, o policial está exposto no trabalho a um contexto de violência, crueldade, brutalidade, mortes, acidentes, assaltos e confronto com armas. Ele intervém em eventos com problemas humanos, diferentes situações de ocorrências que só aumentam o nível de adrenalina. Pela convivência diária com a injustiça social, violência urbana, enfrentando o risco de matar ou de morrer durante 0 atendimento das ocorrências, acaba influenciando diretamente 0 comportamento. Este trabalhador sofre níveis elevados de estresse durante e após o horário de trabalho, estendendo esses sentimentos para outros ambientes nos quais convive. Viver intensamente em risco causa taxa de mortalidade, e, pelas agressões do trabalho, os policiais acabam sendo vítimas dentro e fora da corporação (BRIT0; GOULART, 2005; COUTO; VANDENBERGHE; BRIT0, 2012).

Além de todo 0 estresse desencadeado pela profissão, surgem situações, de caráter organizacional, que dificultam ao policial exercer seu trabalho com tranquilidade, dependendo apenas da própria instituição em que estão inseridos, para serem solucionadas. Dificuldades de relacionamento interno entre os profissionais, desavenças entre colegas, reajustes salariais, insatisfação no trabalho e frustrações que acompanham o sujeito, são fatores que estão ligados ao estresse ocupacional. Trata-se de um trabalhador que está exposto a diferentes tipos de pressões ambientais. Além de estarem em estado de prontidão para combater a criminalidade, ainda precisam acatar ordens institucionais, com grande necessidade de obediência hierárquica, isso causa alto descontentamento pela profissão (AGUIAR, 2007; MINAYO; ADORNO, 2013).

Investigaram-se, em uma pesquisa realizada em Santa Maria, no Estado do Rio Grande do Sul, os níveis de estresse e 0 comprometimento com a carreira de 75 policiais militares. Analisaram-se ambos os sexos dessa profissão. 0s resultados foram os seguintes: $57,3 \%$ dos participantes estavam com sintomas de estresse, sendo que $46,7 \%$ estavam na fase de resistência, $8 \%$ na fase de quase-exaustão, 
2,7\% na fase de exaustão e nenhum participante na fase de alerta. As mulheres apresentaram maiores níveis de estresse e estavam com $72,7 \%$ se comparados com 0 dos homens, que apresentaram $50,9 \%$ de nível de estresse. Assim, verificou-se que a maioria dos participantes, independente do gênero ou área de atuação, encontrava-se na fase de resistência ao estresse (OLIVEIRA; BARDAGI, 2009)

Os governantes acreditam que investir em infraestrutura de materiais, em melhores instalações, adquirir viaturas, rádios, armas e outros diminuirão a criminalidade. Desta forma acabam esquecendo-se de investir no bem-estar do militar, não percebem o quão estressante é 0 exercício da função. Faltam também auxílios por parte das instituições militares que se preocupem com a autoestima, oferta de melhores salários, atendimento médico digno, oportunidades de crescimento no plano de carreira, condições ambientais adequadas, programas de moradia, prevenção de riscos profissionais e uma escala de trabalho mais acessível. (OLIVEIRA; SANTOS, 2010).

Dessa maneira, a saúde é afetada, diminuindo a qualidade de vida, pois a condição de trabalho está inapropriada e insatisfatória. Porém, o policial não pode se demonstrar fragilizado, até se sente mal, mas, pelo status de sua profissão, necessita ser forte, e isso só favorece com o tempo 0 adoecimento do profissional. É um assunto bastante polêmico para os batalhões, gerando certa resistência, uma vez que o policial não admite a existência de problemas emocionais e relata que não precisa de ajuda (SOUZA et al., 2007; GOMES; BELÉM; TELES, 2014).

Práticas inadequadas no ambiente de trabalho causam impacto negativo na saúde física e emocional do trabalhador, provocam baixa motivação, falta de atenção e diminuição de metas, criam pontos negativos e repercutem na vida profissional da pessoa. 0 ideal é adotar técnicas que garantam soluções que proporcionem qualidade de vida no trabalho. Investir em programas que busquem promover 0 bemestar e a integração da instituição com 0 trabalhador para possibilitar 0 equilíbrio entre as expectativas profissionais e sociais do indivíduo. (SEIDEL; ZANNON,
2004; MINAYO; ADORNO, 2013).

Prevenir é uma estratégia importante para lidar com 0 estresse. Inicialmente, a pessoa deverá reconhecer os estressores pessoais. É uma maneira ideal para que esse fato não prejudique de forma negativa o trabalho. Também é necessário interpretar de maneira positiva as situações estressoras, pois essa ação auxiliará no gerenciamento do nível de estresse. Pode ser difícil verificar o estresse no trabalho, pelos estressores pessoais que cada trabalhador traz consigo. Sabe-se que, quando a pessoa sente-se estressada, é possível que ela encontre formas de controlar esse mal, reagindo de maneira saudável a fim de prevenir 0 aparecimento das doenças (GREENBERG, 2002; SERVINO; NEIVA; CAMPOS, 2013).

Ter consciência do processo emocional também ajuda a administrar 0 estresse. Para isso acontecer, é necessária, muitas vezes, a ajuda de um profissional da área da psicologia para auxiliar o indivíduo a cessar a sensação de desconforto e ter consciência do problema (LAVINSKY, 1990; KIENEN; MITSUEKUBO; BOTOMÉ, 2013). Quanto mais equilibrado for 0 organismo, mais saudável será a vida do indivíduo. Para isso acontecer, é importante descobrir a causa do estresse e tentar afastá-lo de alguma maneira (MELEIRO, 2003; MORAES, 2012).

Técnicas de autocontrole são necessárias para manejar 0 estresse. Saber realizar a respiração diafragmática é importante, pois ela proporciona um nível de relaxamento digno, capaz de aumentar a retenção de energia, melhorar a concentração e obter maior capacidade paralidar com o estresse, controlando as emoções. Cita-se, também, o "biofeedback", que é considerado como um novo método preventivo de autocontrole. A pessoa aprende a regular, relaxar e a modificar seus processos fisiológicos, ensina a mente a controlar o corpo, regulando o seu estado físico e emocional. 0 indivíduo aprende a organizar suas reações ao estresse, como: controlar a tensão muscular, pressão arterial, temperatura das mãos e dos pés, atividade cerebral e a frequência cardíaca. Saber manejar essas reações fisiológicas auxiliará na aquisição de saúde (ROSSI, 2004; SANDES, 2013). 
Neste sentido, como objetivo geral da pesquisa, o estudo buscou averiguar como 0 estresse no trabalho afeta a vida dos policiais militares de uma cidade do vale do Paranhana, interior do Estado do Rio Grande do Sul. Já os objetivos específicos estiveram relacionados com as seguintes questões: identificar se 0 policial militar apresenta alto nível de estresse; averiguar se existe diferença nos níveis de estresse entre o policial que realiza serviço externo e o policial que realiza serviço administrativo; verificar as situações do cotidiano de trabalho do policial militar que podem levar ao estresse; verificar os prejuízos físicos, sociais e emocionais que estão relacionados com o estresse no trabalho do policial militar; investigar as estratégias que os policiais militares utilizam para lidar com 0 estresse.

\section{MÉTODO}

A presente pesquisa trata-se de um estudo de corte transversal descritivo, com coleta prospectiva dos dados de caráter quantitativo e qualitativo. 0 modelo quantitativo demonstra-se por métodos, símbolos numéricos, proporcionalidades ou não, escalas usadas para medir as variáveis diante dos sistemas que compõem a natureza, viabilizando a formulação, a descrição e a solução de um determinado problema. Tem como característica permitir uma abordagem focalizada, pontual e estruturada e a coleta de dados quantitativos se realiza pela obtenção de respostas estruturadas Na pesquisa qualitativa, busca-se uma compreensão particular daquilo que se estuda (do fenômeno), não buscando generalizações (CRESWELL, 2009; CRESWELL; CLARK, 2013).

Participaram desta pesquisa 40 policiais militares, população total de um batalhão de operações, que exercem sua função em uma cidade da região do vale do Paranhana, interior do Estado do Rio Grande do Sul. Foi escolhido o batalhão de operação por critério de conveniência, sendo que toda a população deste batalhão de militares estava disponível para participar do estudo. 0 único critério de inclusão adotado foi que tivessem, no mínimo, três meses de atuação na função. Dos 40 policiais entrevistados (quantidade total dos profissionais deste batalhão) $92,5 \%$ (37 pessoas) foram do sexo masculino, e 7,5\% (03 pessoas) foram do sexo feminino.

A pesquisa foi dividida em dois estudos. No estudo 1 (Quantitativo), foi utilizado 0 instrumento EVENT (Escala de Vulnerabilidade ao Estresse no Trabalho). A escala é composta por situações de trabalho, sendo que o sujeito registra suas respostas na folha apropriada. A escala EVENT é divida em três fatores. 0 fator I: clima e funcionamento organizacional; fator II: pressão do trabalho; fator III: infraestrutura e rotina (SIST0 et al. 2012). A escala não se encontra em anexo por se tratar de instrumento psicológico.

A partir dos dados obtidos com a escala EVENT, foi aplicada, entre os participantes que apresentaram maior vulnerabilidade ao estresse (total de 8), uma entrevista semi-estruturada (Estudo 2, de caráter qualitativo), contendo cinco questões abertas, a fim de identificar os prejuízos causados pelo estresse nos aspectos físico, social e emocional, identificados pelo indivíduo. Como critério de participação no Estudo 2, os participantes deveriam apresentar percentil superior (indicando estresse). Esse instrumento também auxiliou a conhecer as estratégias utilizadas pelos policiais militares para lidar com o estresse.

0 projeto seguiu as orientações das resoluções 466/2012 do Conselho Nacional de Saúde (CNS) e a 026/2000 do Conselho Federal de Psicologia(CFP) sobre pesquisas com seres humanos. Depois de aprovado o projeto pelo Comitê de Ética e Pesquisa (CEP), das Faculdades Integradas de Taquara (FACCAT), sob 0 número 694, iniciou-se a coleta de dados seguindo os critérios éticos da pesquisa. Cada policial recebeu o Termo de Consentimento Livre e Esclarecido - TCLE que foi lido e assinado pelos policiais interessados.

Os resultados do estudo 1 foram analisados e tabulados através do programa SPSS 20.0 (Statistical Program for Social Sciences) e do manual da escala). Os dados coletados no estudo 2, foram analisados de acordo com o método de análise de conteúdo de Bardin (2009). Esse método corresponde a um conjunto de 
técnicas de análise das comunicações com 0 objetivo de obter processos sistemáticos de descrição do conteúdo das mensagens analisadas e indicadores que permitam a inferência de conhecimentos a partir dos resultados encontrados. A técnica de análise de conteúdo compõe-se de três etapas: 1) a pré-análise; 2) a exploração do material; 3) 0 tratamento dos resultados e interpretação.

\section{ANÁLISE E DISCUSSÃO DOS RESULTADOS}

\subsection{ESTUD0 1}

A análise dos dados do estudo 1, obtida por meio do instrumento EVENT, permitiu a classificação da pontuação geral da escala em categorias do estresse, conforme descrição do manual. Nomearamse as mesmas de inferior, médio inferior, médio, médio superior e superior. Conforme a classificação da escala, considera-se que $20 \%$ dos policiais militares apresentaram um nível de estresse superior, sendo oito participantes, todos do sexo masculino, estando expostos à vulnerabilidade no local de trabalho. Verificando as demais categorias, $10 \%$ (04 pessoas) dos participantes classificaram-se no nível inferior, $25 \%$ (10 pessoas) no médio inferior, 7,5\% (03 pessoas) no nível médio, e a maior parte dos participantes classificaram-se no nível médio superior, demonstrando uma porcentagem de $37,5 \%$

Tabela 1. Nível de estresse

\begin{tabular}{lcccc}
\hline \multicolumn{1}{c}{ Classificação } & Frequência & Percentil & Percentil válido & Percentil cumulativo \\
\hline Inferior & 4 & 10,0 & 10,0 & 10,0 \\
Médio inferior & 10 & 25,0 & 25,0 & 35,0 \\
Médio & 3 & 7,5 & 7,5 & 42,5 \\
Médio superior & 15 & 37,5 & 37,5 & 80,0 \\
Superior & 8 & 20,0 & 20,0 & 100,0 \\
Total & 40 & 100,0 & 100,0 & \\
\hline
\end{tabular}

Fonte: Dados da pesquisa

(15 pessoas), conforme Tabela 1 - Nível de estresse.

Esses dados permitem verificar que $57,5 \%$ (23 pessoas) da amostra encontram-se acima do nível médio de estresse indicado, mostrando que a maior parte dos policiais que participaram da pesquisa sofre de algum grau de estresse. A profissão do policial militar é uma atividade de alto risco para a vida desse trabalhador, pela própria natureza do trabalho, expondo este profissional a desgaste físico, mental e emocional em sua prática profissional, sendo que 0 ambiente de trabalho apresenta características intensas que só aumentam o nível de estresse, pois esse profissional age em qualquer tipo de situação que mostre perigo, causando com 0 tempo situações de desgaste psicológico (BRITO; GOULART, 2005; COUTO;
VANDENBERGHE; BRITO, 2012).

Outra análise realizada com os dados coletados por meio do EVENT comparou o estresse entre os policias militares que realizam serviço externo com os policiais que realizam 0 serviço administrativo (Gráfico 1). № serviço externo, 32,1\% (09 pessoas) apresentaram estar no nível inferior, médio inferior e médio, não tendo prejuízos no nível de estresse. Já no serviço administrativo, 66,6\% (08 pessoas) estão no nível inferior, médio inferior e médio. É possível considerar, então, que 0 serviço administrativo concentra 0 maior número de profissionais que não sofrem com os níveis consideráveis altos de estresse. No serviço externo, $67,9 \%$ (19 pessoas) estão caracterizados no nível médio superior e superior, e, no serviço administrativo, 33,4\% (04 pessoas) estão localizados no nível médio 


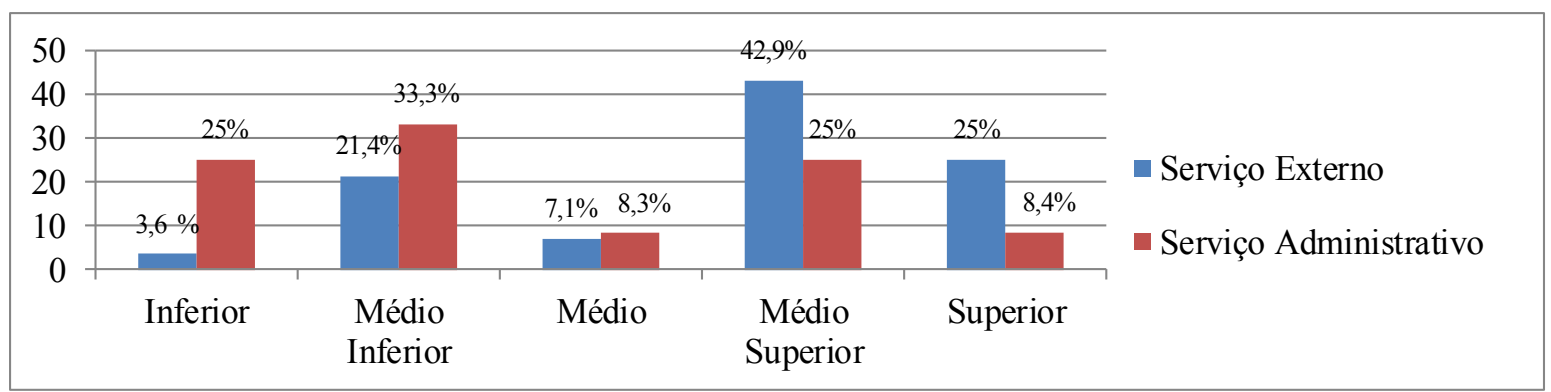

Gráfico 1. Estresse serviço externo e serviço administrativo

superior e superior.

Percebe-se que, dos oito policiais militares que se enquadraram no nível superior de estresse, sete exercem a profissão no serviço externo (25\%) e apenas um policial realiza serviço administrativo $(8,4 \%)$. Assim, nota-se que o serviço externo tem maiores prejuízos de estresse quando comparado com o serviço administrativo. Comprova-se a hipótese para essa amostra de estudo que os policias que fazem serviço externo têm nível de estresse mais alto se comparados com os policiais que fazem o serviço administrativo.

Sabe-se que os indivíduos são diferentes uns dos outros, por isso alguns conseguem lidar com as situações de trabalho desgastantes sem nenhum problema, mas, para outros trabalhadores, 0 estresse pode ser crônico, causando consequências graves para a saúde. Acredita-se que as pessoas que estão mais propensas ao estresse, são aquelas que não conseguem ou não se permitem relaxar, estão em constante estado de tensão. Por este fato 0 estresse está relacionado por seis principais causas de morte: doença cardíaca, acidentes, cirrose do fígado, complicações pulmonares, câncer e suicídio.
Aproximadamente, $75 \%$ a $90 \%$ das consultas médicas estão relacionadas a doenças e queixas do estresse ocupacional (STRAUB, 2005; MEYER et al., 2012).

$\mathrm{Na}$ investigação com a escala EVENT com os policias militares levou-se em conta os três fatores, sendo o primeiro nomeado como clima e funcionamento organizacional (Gráfico 2). Esse item diz respeito ao ambiente físico inadequado, dificuldades pessoais com a chefia, falta de plano de cargos e salários e outros. Os resultados apontaram que $57,5 \%$ dos participantes (23 pessoas) apresentaram nível inferior e médio inferior. Também revelaram nível médio superior $25 \%$ (10 pessoas), e 17,5\% (07 pessoas) pontuaram no nível superior. Esses dados identificam que o policial está exposto a situações de vulnerabilidade, 0 que pode ocasionar certa fragilidade ao estresse. Trabalhadores mais vulneráveis são mais sensiveis ao estresse e sentem sobrecargas de forma mais intensa. 0 estresse nesses casos leva à uma falta de capacidade para solucionar algo que seria normal no dia-a-dia. 0 clima organizacional é uma manifestação da cultura da própria organização. Nesse contexto, 0 estresse pode surgir devido ao clima encontrado no ambiente de trabalho onde os indivíduos estão inseridos. A vida no trabalho gera influência sobre esse ambiente,

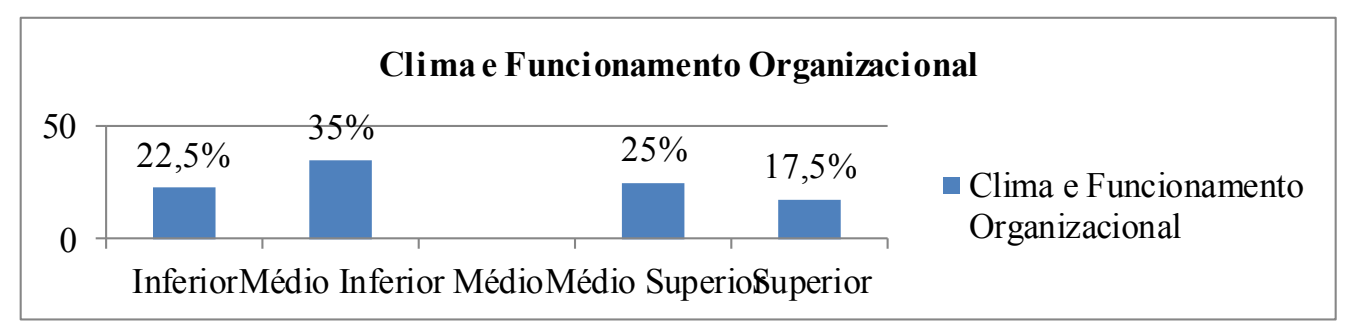

Gráfico 2. Fator 1 - Clima e funcionamento organizacional 
porque são compartilhados pela grande maioria dos trabalhadores, as percepções e crenças pessoais (CANOVA; PORTO, 2010; SALES et al., 2015).

0 fator 2, a pressão no trabalho (Gráfico 3), está relacionado ao acúmulo de funções, realização do trabalho do outro, muita responsabilidade no trabalho diário e outros. Considerou-se que 50\% (20 pessoas) estão no nível inferior, médio inferior e médio, indicando que esses participantes estão expostos a situações menos vulneráveis, tendo menor prejuízo quando se fala em estresse. Também 30\% (12 pessoas) dos entrevistados pontuaram no nível médio superior, e 20\% (08 pessoas) localizaram-se no nível superior.
A desorganização do ambiente organizacional pode colocar em risco a capacidade de rendimento do próprio trabalhador. As condições pioram quando não há clareza nas regras, normas e nas tarefas da instituição, ficando assim expostos a ambientes insalubres e à falta de ferramentas adequadas para 0 trabalho. Então se as exigências institucionais de trabalho, com as quais o profissional se depara no ambiente não forem bem esclarecidas, podem causar estresse. Isso ocorre quando as demandas são reconhecidas pela pessoa como condições de pressão, que extrapolam as situações de controle, indicando maior probabilidade ao desgaste emocional

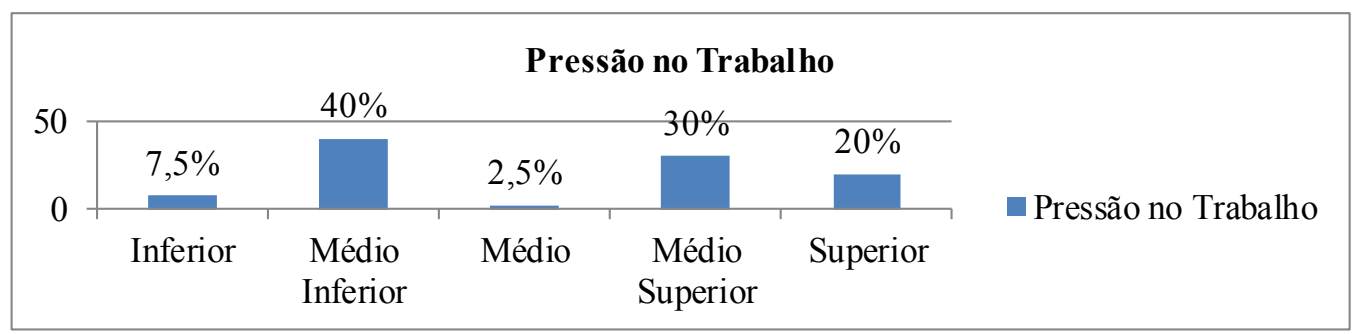

Gráfico 3. Fator 2 - Pressão no trabalho

(FERNANDES et al., 2000; CARRARA; MAGALHÃES; LIMA, 2015).

Já o último fator do instrumento, infraestrutura e rotina (Gráfico 4), está relacionado à falta de equipamentos, materiais precários, mudanças nas horas de trabalho, dobrar jornada e outros. As classificações inferior, médio inferior e médio apresentaram $25 \%$ (10 pessoas), considerando o nível médio superior $32,5 \%$ (13 pessoas) e superior $42,5 \%$ (17 pessoas).

Isso demonstra que as condições adequadas de trabalho poderiam evitar que 0 estresse surja e que cause prejuízos ao trabalhador. É importante que a instituição encontre formas de reduzir os eventos estressores, que estão relacionados com 0 barulho, iluminação, falta de equipamento, temperatura e situações de trabalho. Só desta maneira será possível desenvolver e promover a saúde ao profissional. Portanto, seria muito importante que os responsáveis pela saúde física e mental do militar estivessem atentos às mudanças de comportamento a fim de promover espaços mais saudáveis de trabalho. (ROSSI

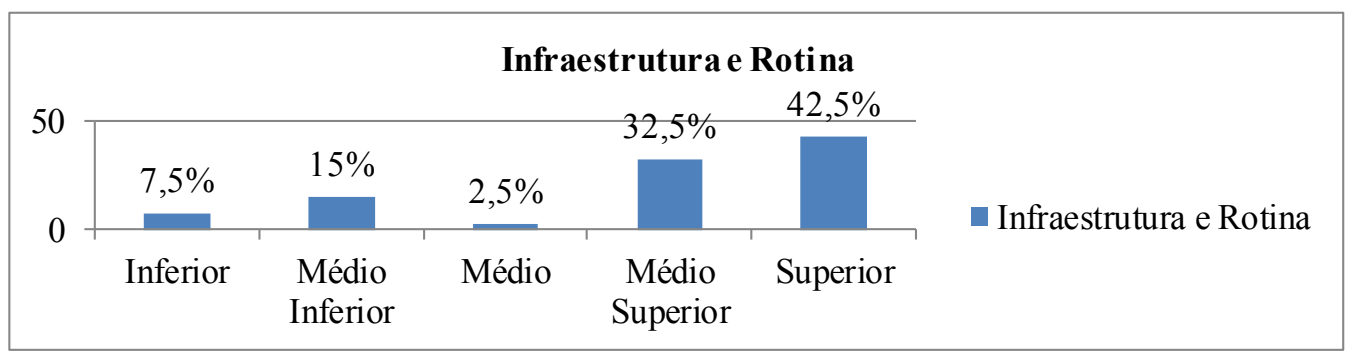

Gráfico 4. Fator 3 - Infraestrutura e rotina 
et al., 2009; RIBEIRO; SANTANA, 2015).

Diante dos fatores da escala apresentados, considerando os níveis superiores, o Clima e Funcionamento Organizacional pontuou 42,5\%, 17 pessoas, que se sentem prejudicadas com as situações vivenciadas nesse contexto. A pressão no trabalho pontuou $50,0 \%, 20$ pessoas, e $75 \%, 30$ pessoas, apresentaram prejuízos na infraestrutura e rotina. Percebe-se, então, que a infraestrutura e rotina são 0 fator em que está concentrado 0 maior número de policiais militares que demonstraram insatisfação pelas situações que enfrentam em seu local de trabalho, desencadeando, assim, 0 estresse em nível superior.

0 ambiente desfavorável constitui em um processo de investigação, principalmente dos hábitos mentais e emocionais do indivíduo que regem tais experiências do trabalho. Cada pessoa lida de uma forma aos eventos expostos, alguns mais conscientes, desenvolvendo maior habilidade para lidar com 0 estresse. Então, cada ser humano enfrenta e interpreta de maneira diferente as situações que desencadeiam a reação do estresse. Deve-se levar em conta aquilo que a pessoa está passando no momento, uma vez que tudo dependerá de como 0 indivíduo avalia 0 evento a que está exposto. Isso significa que 0 que é estressante para um talvez não seja estressante para 0 outro (SIMMONS, 2000; MORAES, 2012).

\subsection{ESTUD0 2}

0 estudo 2 analisou a entrevista semiestruturada realizada com oito participantes, que tiveram a classificação do nível de estresse superior, conforme a aplicação do estudo 1. Foram identificadas seis categorias de análise a partir das entrevistas: a definição de estresse, principais causadores de estresse, prejuízos físicos, prejuízos sociais, prejuízos emocionais e estratégias de enfrentamento, que estão descritas na tabela abaixo.
Quadro 1. Categoria da análise das entrevistas

\begin{tabular}{|c|c|c|}
\hline Categoria & $\begin{array}{l}\text { Categoria de } \\
\text { análise }\end{array}$ & Unidade de registro \\
\hline \multirow{3}{*}{$\begin{array}{c}\text { Categoria } \\
1\end{array}$} & \multirow{3}{*}{$\begin{array}{l}\text { Definição de } \\
\text { estresse }\end{array}$} & Sobrecarga física \\
\hline & & Problemas emocionais \\
\hline & & $\begin{array}{l}\text { Situações ambientais } \\
\text { adversas }\end{array}$ \\
\hline \multirow{5}{*}{$\begin{array}{l}\text { Categoria } \\
\quad 2\end{array}$} & \multirow{5}{*}{$\begin{array}{c}\text { Principais } \\
\text { causadores de } \\
\text { estresse }\end{array}$} & Carga horária \\
\hline & & Baixa remuneração \\
\hline & & $\begin{array}{l}\text { Falta de reconhecimento da } \\
\text { comunidade }\end{array}$ \\
\hline & & $\begin{array}{l}\text { Falta de reconhecimento dos } \\
\text { superiores }\end{array}$ \\
\hline & & $\begin{array}{l}\text { Falta de equipamentos, } \\
\text { viaturas, armas }\end{array}$ \\
\hline \multirow{4}{*}{$\begin{array}{l}\text { Categoria } \\
\quad 3\end{array}$} & \multirow{4}{*}{$\begin{array}{l}\text { Prejuízos } \\
\text { físicos }\end{array}$} & Dor no corpo \\
\hline & & Dor de cabeça \\
\hline & & Dificuldade para dormir \\
\hline & & Cansaço físico e mental \\
\hline \multirow{3}{*}{$\begin{array}{l}\text { Categoria } \\
\qquad 4\end{array}$} & \multirow{3}{*}{$\begin{array}{l}\text { Prejuízos } \\
\text { sociais }\end{array}$} & $\begin{array}{l}\text { Problemas relacionamento } \\
\text { conjugal }\end{array}$ \\
\hline & & $\begin{array}{l}\text { Pânico em frequentar outros } \\
\text { ambientes }\end{array}$ \\
\hline & & $\begin{array}{l}\text { Divergências de opiniões com } \\
\text { colegas }\end{array}$ \\
\hline \multirow{5}{*}{$\begin{array}{l}\text { Categoria } \\
\quad 5\end{array}$} & \multirow{5}{*}{$\begin{array}{l}\text { Prejuízos } \\
\text { emocionais }\end{array}$} & Irritação \\
\hline & & Tristeza \\
\hline & & Agressividade \\
\hline & & Solidão \\
\hline & & Desânimo \\
\hline \multirow{6}{*}{$\begin{array}{l}\text { Categoria } \\
\mathbf{6}\end{array}$} & \multirow{6}{*}{$\begin{array}{l}\text { Estratégias de } \\
\text { enfrentamento }\end{array}$} & $\begin{array}{l}\text { Atendimento psicológico e } \\
\text { psiquiátrico }\end{array}$ \\
\hline & & Grupo de apoio \\
\hline & & $\begin{array}{l}\text { Faculdade a distância e } \\
\text { presencial }\end{array}$ \\
\hline & & $\begin{array}{l}\text { Exercício físico (caminhada, } \\
\text { natação, corrida) }\end{array}$ \\
\hline & & Convívio com a família \\
\hline & & Conversar com amigos \\
\hline
\end{tabular}

Fonte: Dados da pesquisa 
policial entende por estresse. Os principais fatores citados pelos participantes foram: a sobrecarga física, problemas emocionais e situações ambientais adversas, como exemplificado na seguinte fala: "Estresse é quando o corpo está sobrecarregado, ultrapassando todos os limites." (Sujeito 1). 0 estresse é considerado um cansaço físico ou mental que está relacionado à grande quantidade de trabalho ou a preocupações. São situações que estão desconectadas com a realidade do sujeito e que são propícias a desencadear sintomas negativos (FREITAS, 2009; MAFFIA; ZILLE, 2013). Sabe-se que cada pessoa tem uma compreensão subjetiva sobre 0 estresse, mas se verifica que os participantes têm o entendimento que 0 estresse causa prejuízos à saúde.

A categoria 2 buscou identificar os principais causadores de estresse. As situações de trabalho relatadaspelosparticipantesforamasseguintes:acarga horária, baixa remuneração, falta de reconhecimento da comunidade, falta de reconhecimento dos superiores, falta de equipamentos, viaturas, armas, como explicitado nas seguintes falas: "A carga horária, não ser reconhecido como profissional. Você tem uma sugestão para realizar um tipo de serviço e chega o teu superior e diz como você deve fazer. Você faz para não ser punido, mas sabe que irá dar errado." (Sujeito 2). 0 sujeito 3 reforça as principais situações que causam estresse: "Me perturba a falta de infraestrutura, não ter viatura, armas, equipamentos adequados para exercer a função. A comunidade também não reconhece 0 teu trabalho como profissional, só sabe julgar. Temos uma carga horária excessiva, recebemos pouco, arriscamos nossas vidas em troca de julgamentos." A sobrecarga de trabalho pode ser percebida como um fator ao surgimento de estresse patológico na função desempenhada. A sobrecarga dos estímulos estressores excedem às exigências de adaptação diante do ambiente. Assim as situações vulneráveis estão presentes na rotina do policial, como o excesso de trabalho, poucas horas de descanso, má alimentação, baixa remuneração, falta de reconhecimento, jornada dupla de trabalho e outros. Todas essas situações citadas colaborarão para 0 surgimento de doenças, que estão relacionadas diretamente ao estresse por realizar essa prática profissional (COSTA et al., 2007; OLIVEIRA; CUNHA, 2014). Nota-se que algumas situações citadas nas entrevistas também são identificadas no fator infraestrutura e rotina que apareceram com percentual elevado na escala EVENT.

Dentro da categoria 3, prejuízos físicos, os policiais militares identificaram que sentem dor no corpo, dor de cabeça, dificuldade para dormir e cansaço físico e mental. Essas condições podem ser percebidas na fala do participante: "Não consigo dormir, por isso comecei a tomar bebida destilada para pegar no sono. Tenho a sensação que estou sempre cansado, acordo muitas vezes com dor de cabeça." (Sujeito 2). As manifestações do estresse podem ser de ordem fisiológica (dor de cabeça, hipertensão, taquicardia), psicológica (insatisfação com 0 trabalho, ansiedade, depressão) ou comportamental (tabagismo, abuso de drogas, álcool, absenteísmo). 0 desgaste emocional ao qual a pessoa é submetida em suas relações de trabalho é um fator que deve receber atenção, de acordo com as manifestações das angústias, frustrações e emoções do trabalhador. Muitas vezes por causa das regras sociais, normas da instituição as pessoas acabam ficando presas aos seus sentimentos e são incentivadas a aparentar sempre um comportamento emocional não compatível aos seus reais sentimentos (DEMINCO, 2011; FIGUEIRED0; CASTR0, 2015).

$\mathrm{Na}$ categoria 4, prejuízos sociais, os participantes relataram que possuem problemas no relacionamento conjugal, pânico em frequentar outros ambientes e divergência de opiniões com colegas. Tais situações podem ser verificadas na seguinte fala: "Estava tendo problemas com a minha esposa, pessoas do meu convívio, não tinha paciência. Comecei a me trancar dentro de casa, sentia que alguma coisa iria acontecer, entrava em pânico, me convidavam para sair e eu preferia ficar em casa olhando TV. Fiquei encostado por três meses e tiraram minha arma de fogo para não fazer mal a ninguém." (Sujeito 2). Essa situação também aparece na fala deste policial: "Tenho problemas com colegas de trabalho, divergência de 
opiniões, fico quieto para não me incomodar. Tenho problemas com a minha esposa, essa profissão faz com que você seja insensível, quero que as pessoas que estão em minha volta pensem como eu." (Sujeito 8).

0 policial militar não é 0 único que sofre pela situação de estresse provocada pelo trabalho que realiza. No ambiente familiar, o policial, muitas vezes, desliga-se da relação com os membros da sua família e, assim, pela dificuldade de relacionarse com as pessoas de seu lar, acaba afastando-se de todos, demonstrando suas frustrações por meio de atos grosseiros e agressivos com as pessoas que estão a sua volta. Isso ocorre em função de 0 militar estar sempre exposto à adrenalina, pois é preparado para agir, desempenhando sua função. À medida que aumenta 0 nível de tensão, aumenta também 0 nível de vigilância e de expectativa, agindo sempre de forma enérgica, comportamento que é refletido em suas relações pessoais. A função desempenhada aumenta 0 índice de suicídio, divórcio, consumo de bebida alcoólica, uso de medicamentos indevidos, entre outros (SILVA; VIEIRA, 2008; COUTO; VANDENBERGHE; BRITO, 2012).

$\mathrm{Na}$ categoria 5, os prejuízos emocionais apareceram nas falas dos entrevistados. Sentimentos de irritação, tristeza, agressividade, solidão, desânimo são percebidos nas falas dos militares, conforme relata 0 sujeito 2:"Fico irritado, tenho uma agressividade alta, queria fazer justiça com as próprias mãos, quero resolver os problemas do mundo, pensava em matar quem fazia algo de ruim, pois na brigada tu é preparado para defendera comunidade." Essa situaçãoé reforçada pelo sujeito 7: "Tenho sentimento de solidão, me sinto triste na maior parte do dia." A desorganização no ambiente põe em risco a capacidade do rendimento de trabalho, pois a pessoa não possui condição adequada para realizar a função. A falta de programas voltados à saúde e bem-estar psicológico dos policiais também podem ser agravantes da situação. Entende-se que são necessários programas que venham garantir qualidade de vida aos profissionais que exercem a função de policial militar (DEMINCO, 2011; FELIX; CATÃO, 2013).
Por fim, na categoria 6, as estratégias de enfrentamento, encontrou-se na fala dos participantes que, para lidar com o estresse, muitos buscam, por conta própria, atendimento psicológico/psiquiátrico, frequentam grupo de apoio, realizam faculdade a distância ou presencial, exercício físico (caminhada, natação e corrida), convívio com a família, conversar com amigos. Essa ideia pode ser verificada conforme os relatos a seguir: "Realizo atendimento psicológico e psiquiátrico, participo de um grupo de apoio. Comecei a fazer curso a distância para ocupar a minha cabeça. Hoje também pratico natação." (Sujeito 2). E 0 sujeito 3 relata que: "Antes de começar o serviço faço exercício físico, também tento expor minhas ideias para diminuir o desconforto. Mas o convívio com o filho revigora todas as minhas energias."

São necessárias intervenções saudáveis para minimizar a sintomatologia do estresse. Enfrentar de forma positiva a situação irá oportunizar ao indivíduo a elaboração de um novo padrão de adaptação para as condições de vida atuais. Sabe-se que pequenas estratégias podem fazer toda a diferença na hora de proporcionar qualidade de vida, sendo que algumas estratégias são de fácil alcance, como realizar atividade física, praticar atividades ao ar livre, organizar a agenda, ter boa alimentação, ter boa qualidade de sono, desfrutar de momento de lazer com a família e estipular metas. Nota-se que existe a chance de 0 indivíduo alterar 0 seu padrão de vida estressante, modificando e reajustando os maus hábitos físicos e mentais por atitudes mais saudáveis, buscando a oportunidade de encontrar estratégias para administrar o estresse do dia a dia, que possam promover a saúde, a fim de buscar uma melhor qualidade de vida (PUSTILNICK, 2010; HIRSCH et al., 2015).

\section{CONCLUSÃO}

Os resultados encontrados demonstram que existem situações de vulnerabilidade no local de trabalho do policial militar, causando estresse aos 
profissionais pesquisados. Os resultados do estudo qualitativo corroboram com 0 estudo quantitativo e permitem identificar os sentimentos relacionados ao estresse elevado. Verifica-se, assim, que a qualidade de vida dos policiais militares está prejudicada. Destaca-se que é uma classe trabalhadora que provavelmente encontra-se em um contexto bastante vulnerável, ocasionando desta forma a produção de problemas psíquicos e uma condição psicológica que causa sofrimento.

É fundamental encarar 0 estresse como um agravante das causas dos sintomas que geram prejuízos na vida dos policiais militares. Desta forma os resultados deste estudo se tornam importantes na medida em que identificam os fatores causadores de estresse no trabalho do policial militar, permitindo que sejam desenvolvidas estratégias para 0 suporte emocional e social dos trabalhadores dessa categoria.

Acredita-se que 0 trabalho da psicologia pode favorecer na melhoria da qualidade de vida desses profissionais, visto que a ciência psicológica atua nos âmbitos institucional, organizacional, social e clínico do indivíduo. Recomenda-se que sejam desenvolvidas políticas públicas de apoio a este serviço tão importante, que é a segurança pública, pois o policial militar, estando em seu estado íntegro de saúde, poderá garantir segurança à sociedade com mais qualidade.

Verificaram-se no decorrer da pesquisa algumas limitações. Uma delas foi 0 fato de os dados terem sido coletados em apenas uma cidade do vale do Paranhana e, portanto, os dados não podem ser generalizáveis. Sugere-se para os próximos estudos que sejam investigadas as demais cidades da região, ampliando a pesquisa para outros batalhões.

Entende-se também que este material irá servir para suscitar novas investigações sobre 0 estresse do policial militar. A investigação científica é uma maneira de ampliar a valorização do profissional da área de segurança, como também sensibilizar os dirigentes dessa instituição, para que percebam a necessidade de proporcionar maior qualidade de vida ao policial militar. Criar estratégias de valorização à saúde física e psíquica do policial, já que são profissionais fundamentais para a comunidade, se faz fundamental.

\section{REFERÊNCIAS}

AGUIAR, F. L. S. Estresse ocupacional: contribuições das pirâmides coloridas de Pfister no contexto policial militar. 2007. 94f. Dissertação (Mestrado em Psicologia) - Universidade Federal do Pará, Belém, 2007.

BARDIN, L. Análise de conteúdo. Lisboa: Edições 70, 2002.

BRIT0, D. P.; GOULART, I. B. Avaliação psicológica e prognóstico de comportamento desviante numa corporação militar. PsicoUSF, Itatiba, v. 10, n. 2, p. 149-160, dez. 2005.

CALANZAS, M. E. Resenha. Cadernos de saúde pública, Rio de Janeiro, v. 26, n. 1, p. 206-211, jan. 2010.

CAMEL0, S. H. H.; ANGERAMI, E. L. S. Riscos Psicossociais Relacionados ao Trabalho das Equipes de Saúde da Família: Percepções dos Profissionais. Revista de Enfermagem UERJ, Rio de Janeiro, v. 15, n. 4, p. 502-7. out./dez. 2007.

CARRARA, G. L. R.; MAGALHÃES, D. M.; LIMA, R. C. Riscos ocupacionais e os agravos à saúde dos profissionais de enfermagem. Revista Fafibe OnLine, Bebedouro, v.8, n.1, p.265-286, 2015.

CANOVA, K. R.; PORT0, J. B. 0 Impacto dos Valores Organizacionais no Estresse Ocupacional: Um Estudo com Professores de Ensino Médio. Revista de Administração Mackenzie, São Paulo, v. 11, n. 5. p. 4-31, set./out. 2010.

COSTA, M. A.; ACCIOLY JUNIOR, H.; OLIVEIRA J.; MAIA E. Estresse: diagnóstico dos policiais militares em uma cidade brasileira. Revista Panamericana de Salud Pública, Washington, v. 21, n. 4, p. 217-22, 2007.

COUTO, G.;VANDENBERGHE, L.; BRITO, EA G. Interações interpessoais e estresse entre policiais militares: 
um estudo correlacional. Arquivos Brasileiros de Psicologia, Rio de Janeiro, v. 64, n. 2, p. 47-63, 2012.

CRESWELL, J. W. Projeto de pesquisa: Métodos qualitativo, quantitativo e misto. 3. ed. São Paulo: Artmed, 2009.

CRESWELL, J. W.; CLARK, V. L. Plano. Pesquisa de métodos mistos. 2. ed. Porto Alegre: Pesno, 2013.

DEMINCO, M. Jornada de trabalho e redução de estresse. Psicologado, 2011. Disponível em: <http:// psicologado.com/atuacao/psicologia-organizacional/ jornada-de-trabalho-e-reducao-do-estresse $>$. Acesso em: 06 abr. 2014.

FELIX, Y. T. M.; CATÃO, M. F. F. M. Envelhecimento e aposentadoria por policias rodoviários. Psicologia \& Sociedade, Belo Horizonte, v. 25, n. 2, p. 420-429, 2013.

FERNANDES, S. R. P.; DI PACE, D. M. T.; PASSOS, M. F. D. Organização e condições de trabalho em telemarketing: repercussões na saúde psíquica dos trabalhadores. Bahia: Departamento de Psicologia/ UFBa, 2000.

FERREIRA, J. J.; OLIVEIRA, P. L. Saúde mental no trabalho: coletânea do fórum de saúde e segurança no trabalho do Estado de Goiás. Goiânia: Cir Gráfica, 2013.

FERREIRA, M. C.; MENDONÇA H. Saúde e Bem-estar no trabalho: dimensões individuais e culturais. São Paulo: Casa do Psicólogo, 2012.

FIGUEIRED0, J. 0.; CASTR0, E. E. C. Ajustamento criativo e estresse na hipertensão arterial sistêmica. Revista Abordagem Gestalt, Goiânia, v.21, n.1, jun. 2015.

FREITAS, S. M. P. 0 psicólogo do trabalho no mundo das práxis capitalista: reflexões fenomenológicoexistenciais. Revista da Abordagem Gestáltica,
Goiânia, v.15, n.2, dez. 2009.

GOMES, C. M.; AZAMBUJA, J. S. Estresse e enfermagem: estudo de casos. 2009. Trabalho de Conclusão de Curso (Graduação em Psicologia) Faculdades Integradas de Taquara, Taquara, 2009.

GOMES, D. F. S.; BELÉM, A. 0.; TELES, S. S. Saúde mental de militares: uma revisão integrativa do cenário brasileiro. Revista de Saúde Pública, Florianópolis, v. 7, n. 3, p. 88-102, set./dez. 2014.

GOMES, R. etal.Associação entre o nível de estresse e 0 nível educacional de funcionários de uma universidade pública. In: ENCONTRO DE ENSINO, PESQUISA E EXTENSÃO, PRESIDENTE PRUDENTE, 2013.

GREENBERG, J. S. Administração do estresse. 6. ed. São Paulo: Manole, 2002.

LAVINSKY, L. Saúde: informações básicas. 2.ed. Porto Alegre: UFRGS, 1990.

LIPP, M. E. N. 0 stress está dentro de você. 2. ed. São Paulo: Contexto, 2000.

LIPP, M. E. N. Manual do inventário de sintomas de stress para adultos de Lipp (ISSL). São Paulo: Casa do Psicólogo, 2000.

LIPP, M. E. N. Mecanismos neuropsicofisiológicos do stress: teoria e aplicações clínicas. São Paulo: Casa do Psicólogo, 2003.

LIPP, M. E. N. Mecanismos neuropsicofisiológicos do stress: teoria e aplicações clínicas. 3. ed. São Paulo: Casa do Psicólogo, 2010.

LIPP, M. E. N. Manual do inventário de sintomas de stress para adultos de Lipp. São Paulo: Casa do Psicólogo, 2014.

HIRSCH, C. D. et al. Preditores do estresse e estratégias de coping utilizadas por estudantes de Enfermagem. Acta paulista de enfermagem, São Paulo, v.28, n.3, 
maio/jun. 2015.

KIENEN, N.; MITSUEKUBO, 0.; BOTOMÉ, S. P. Ensino programado e programação de condições para 0 desenvolvimento de comportamentos: alguns aspectos no desenvolvimento de um campo de atuação do psicólogo. Acta comportamentalia, Guadalajara, v.21, n.4, 2013.

MAFFIA, L. N.; ZILLE, L. P. Estresse ocupacional e gestores: estudo nas secretarias de estado de Minas Gerais. Belo Horizonte: CEPEAD/UFMG, 2013.

MALAGRIS, L. E. N; FIORITO, A. C. C. Avaliação do nível de estresse de técnicos da área de saúde. Estudos de Psicologia, Natal, v. 23, n. 4, p. 391-398, 2006.

MALLAR, S. C.; CAPITÃO, C. G. Burnout e hardiness: um estudo de evidência de validade. Psico-USF, Itatiba, v. 9, n. 1, p. 19-29, jan./jun. 2004.

MARRAS, J. P.; VELOSO, H. M. Estresse ocupacional. Rio de Janeiro: Elsevier, 2012.

MARQUES, C. P.; GASPAROTTO, G. S.; COELHO, R. W. Líquen plano oral: reconhecendo a doença e suas características básicas. SALUSVITA, Bauru, v. 34, n. 1, p. 99-108, 2015.

MELEIRO, A. M. A. S. Stress. Entrevista concedida a Drauzio Varella. 24 maio 2003. Disponível em: <http:// drauziovarella.com.br/entrevistas-2/estresse/>. Acesso em: 10 abr. 2014.

MEYER C. et al. Qualidade de vida e estresse ocupacional em estudantes de medicina. Revista Brasileira de Educação Médica, Rio de Janeiro, v.36, n.4, out./dez. 2012.

MINAYO, M. C. S.; ADORNO, S. Risco e (in)segurança na missão policial. Ciência \& Saúde Coletiva, Rio de Janeiro, v.18, n.3, p.585-593, 2013.

MORAES,A.P.P.Stress,sintomasfísicos,psicológicos e enfretamento de situações estressoras em profissionais da saúde que atuam em hospitais.
2012. Dissertação (mestrado) - Universidade Estadual Paulista, São Paulo, Campus de Bauru, SP.

OLIVEIRA, K. L.; SANTOS, L. M. Percepção da saúde mental em policiais militares da força tática e de rua. Sociologias, Porto Alegre, v.12, n.25, set./dez. 2010.

OLIVEIRA, P. L. M.; BARDAGI, M. P. Estresse e comprometimento com a carreira em policiais militares. Bol. Psicol., São Paulo, v. 59, n. 131, dez. 2009.

OLIVEIRA, R. J.; CUNHA, T. Estresse do profissional de saúde no ambiente de trabalho: causas e consequências. Caderno Saúde e Desenvolvimento, Curitiba, v. 3, n. 2, jul./dez. 2014.

PAIVA, K. C. M.; GOMES, M. Â. N.; HELAL, D. H. Estresse ocupacional e síndrome de burnout: proposição de um modelo integrativo e perceptivas de pesquisa junto a docentes do ensino superior. Gestão \& Planejamento, Salvador, v. 16, n. 3, p. 285-309, set./dez. 2015.

PUSTILNICK, R. Administração do estresse: qualidade de vida: Dicas para uma vida saudável e produtiva. Curitiba: Ibpex, 2010.

RAMIR0, F. C. et al. Investigação do estresse, ansiedade e depressão em mulheres com fibromialgia: um estudo comparativo. Revista Brasileira de Reumatologia, São Paulo, v.54, n.1, jan./fev. 2014.

RANGÉ, B. Psicoterapia cognitivo-comportamental. Porto Alegre: Artmed. 2001.

RIBEIRO, L. A.; SANTANA, L. C. Qualidade de vida no trabalho: fator decisivo para o sucesso organizacional. Revista de Iniciação Científica, Cairu, v. 2, n. 2, p. 75-96, jun. 2015.

ROSSI, A. M. Estresse masculino. Porto Alegre: Artes e Ofícios, 2004.

ROSSI, A. M.; QUICK, J. C.; PERREWÉ, P. L. Stress e qualidade de vida no trabalho. São Paulo: Atlas, 2009. 
SADIR, M. A.; LIPP, M. E. N. As fontes de estresse no trabalho. Revista de Psicologia da IMED, Passo Fundo, v. 1, n. 1, p. 144-126, 2009.

SALES, A. C. F. et al. Clima organizacional e estresse laboral. Revista Fafibe On-Line, Bebedouro, v. 8, n. 1, p. 1-14, 2015.

\section{SAMPAIO, J. R.; GALASSO, L. M. R. Stress no mundo} do trabalho: Trajetória conceitual. São Paulo: Atlas, 2002.

SANDES, W. F. Uso do biofeedback no treinamento policial. Revista Brasileira de Segurança Pública, São Paulo, v. 7, n. 1, p.166-180, fev./mar. 2013.

SEIDEL, E. M. F.; ZANNON, C. M. L. C. Qualidade de vida e saúde: aspectos conceituais e metodológicos. Cadernos de Saúde Pública, Rio de Janeiro, v. 20, n. 2, p. 580-588, 2004.

SELYE, H. Stress: a tensão da vida. São Paulo: Ibrasa, 1965.

SELYE, Hans. The stress of life. New York: McGraw Hill, 1984.

SERVINO, S.; NEIVA, E. R.; CAMPOS, R. P. Estresse ocupacional e estratégias de enfrentamento entre profissionais de tecnologia da informação. Revista Interinst. Psicol., Belo Horizonte, v. 6, n. 2, jul.2013.

SILVA, M. B.; VIEIRA, S. B. 0 processo de trabalho do Militar Estadual e a Saúde Mental. Saúde e Sociedade, São Paulo, v. 17, n. 4, p. 161-170, 2008.

SIMMONS, R. Estresse: esclarecendo suas dúvidas. São Paulo: Ágora, 2000.

SISTO, F. F. et al. Escala de Vulnerabilidade ao Estresse no Trabalho (EVENT). São Paulo: Vetor, 2012.

SOUZA, E. R. et al. Sofrimento psíquico entre policiais civis: uma análise sob a ótica de gênero. Cadernos de Saúde Pública, Rio de Janeiro, v. 23, n.1, p.105-114, 2007.
SOUZA, E. R. et al. Fatores associados ao sofrimento psíquico de policiais militares da cidade do Rio de Janeiro, Brasil. Cadernos de Saúde Pública, Rio de Janeiro, v.28, n.7, 2012.

SPSS STATISTICS PROFESSIONAL. Disponível em: $<$ http://www03.ibm.com/software/products/pt/spssstats-pro>. Acesso em: 14 jul. 2014.

STRAUB, R. 0. 0. Psicologia da Saúde. Porto Alegre: Artmed, 2005.

Recebido em: 28 de abril de 2016 Aceito em: 19 de setembro de 2016 